\title{
SOBRE AS SITUAÇÕES DE ENFERMAGEM E SEUS GRAUS DE COMPLEXIDADE - MENOR, MÉDIA E MAIOR - NA PRÁTICA ASSISTENCIAL HOSPITALAR
}

\section{On Nursing situations and degrees of complexity -minor, medium and major in hospital assistance practice.}

\author{
La situación/realidad/contexto de la enfermería y sus grados \\ de complexidad - baja, média y superior en la práctica \\ asistencial hospitalaria
}

\section{RESUMO}

Reflexão sobre o conceito de situação de enfermagem e as variações por graus de complexidade no cotidiano assistencial. Destacamos a importância da compreensão da situação-problema do cliente hospitalizado diante dos graus de complexidade menor, média e maior - com o objetivo principal de estimular a consciência crítica dos estudantes e profissionais de enfermagem. Compreender a complexidade das situações implica a identificação de fenômenos relacionados ao cliente, ambiente e outros que interferem na dinâmica assistencial. Portanto, a abordagem situacional ao cliente incluirá uma associação de fenômenos que estão relacionados ao saber-fazer das enfermeiras, no qual constam também as tomadas de decisões mais pertinentes para as resoluções das situações que surgem na prática. Finalmente, a complexidade das situações não inclui apenas o processo fisiopatológico do cliente, mas um conjunto de fatores, que, de acordo com a experiência dos profissionais e sua associação com fenômenos inclusos no ambiente, determinam o grau de complexidade da situação de enfermagem.

Palavras-chave: Enfermagem. Situações. Assistência.

\begin{abstract}
Reflexion on the concept of nursing situation and variations by degrees of complexity in daily assistance. We point out the relevance in understanding the hospitalized client problemsituation in relations to degrees of complexity - minor, medium and major, aiming to promote the development of nursing professional and students crtitical thought. The understand the complexity of situations require the identification of events involving the patient, the environment and any other that may interfere with the dynamic of assistance. Therefore, the patient situation approach will include various events related to "knowing" and "doing" of nurses and decisions taken to solving situations in the practice. Finally, the complexity of situations does not comprise only the physical and pathological process of the patient, but also the various factors that, according to professional experience and its relation with environment factors, will determine the degree of complexity of nursing situation.
\end{abstract}

Key words: Nursing. Situation. Assistance.

\section{Resumen}

Reflexión sobre el concepto de situación/realidad/contexto de la enfermería y sus variaciones por grado de complexidad en el cotidiano asistencial. Se destacó la importancia de la compresión de la situación-problema del cliente hospitalizado en relación a los grados de complejidad - baja, média y superior, con el objetivo de estimular la conciencia critica de los estudiantes y profesionales de la enfermería. Comprender la complexidad de situaciones que implican la identificación de los fenómenos relacionados con el cliente, con el ambiente y con otros elementos que interfieren en la dinámica asistencial. Por lo tanto, el abordaje situacional del cliente debe incluir una asociación de fenómenos relacionados al saber-hacer de las enfermeras. Son consiradas también la toma de decisiones pertinentes para la solución de situaciones que surgen durante esta practica. Finalmente, la complexidad de las situaciones no incluye apenas el proceso fisiopatológico del cliente, sino también un conjunto de factores que, según la experiencia de profesionales y su relación con fenómenos incluidos en el ambiente, determinan el grado de complexidad de la situación de enfermería.

Palabras-clave: Enfermería. Situación. Asistencia.

'Doutora em Enfermagem pela EEAN/UFRJ. Professora Assistente do Departamento de Fundamentos de Enfermagem e Administração da EEAAC/UFF. Brasil. E-mail: gisellaqueluci@yahoo.com.br. ${ }^{2}$ Doutora em Enfermagem pela EEAN/UFRJ. Diretora da Escola de Enfermagem Alfredo Pinto/ UNIRIO. Brasil. E-mail: nebia@unirio.br 
Situações de enfermagem e graus de complexidade Queluci GC, Figueiredo NMA

\section{INTRODUÇÃO}

Trata-se de uma reflexão crítica sobre as situações de enfermagem e a variação de graus de complexidade - menor, média e maior - no cotidiano da prática assistencial hospitalar. 0 objetivo principal é aprimorar nossa compreensão do sentido essencial da Enfermagem na prática da assistência à saúde, principalmente quando se pretende alcançar a explicação possível e condizente com a objetividade daquilo que se entende por situação de enfermagem, - situação-problema -, na casuística assistencial de interesse profissional da prática da enfermagem.

Aimportância da aprendizagem na profissão, dando ênfase às situações de enfermagem, é discutida por Carvalho ${ }^{1}$ nas etapas da mudança empreendida no currículo Novas Metodologias da Escola de Enfermagem Anna Nery da Universidade Federal do Rio de Janeiro - EEAN/UFRJ. A autora ressalta "a integração da teoria à prática, do estudo ao trabalho, do conteúdo à experiência e das atividades planejadas ao encontro vivo com a clientela ou grupos da comunidade"1, e enfatiza:

(...) as experiências de aprendizagem, no novo currículo, são bem mais adequadas à questão do processo de enfermagem, uma vez que o estudante aprende através de novas metodologias de resolver situações-problema no interesse da enfermagem, em vivências de prática e de fato. Experiências estruturantes da prática assistencial e que, de certa forma, servem ainda ao estilo de atividades de cuidar e de atuar consistentes com o exercício da arte profissional, da utilidade e da participação social ${ }^{1: 15}$

Segundo essa autora, “(...) a situação de enfermageme seu grau de complexidade podem ser percebidos no plano do encontro enfermeira-cliente", ' haja vista que as enfermeiras, habitualmente ao prestarem cuidados, manifestam dificuldades em determinar condutas adequadas diante da atribuição de causalidade em relação às condições específicas e aspectos afetados, ou diante dos graus de complexidade - menor, média e maior - nas situações envolvendo os problemas dos clientes hospitalizados.

A autora destaca, ainda, a necessidade de aplicação metodológica para a resolução de problemas emergentes das situações dos clientes, e que sejam "compatíveis com a pragmática das funções de enfermagem e ampliação do papel profissional"2. Nesse sentido,

A metodologia de resolução de situações-problema foi escolhida como a mais acertada para a
Esc Anna Nery Rev Enferm 2010 jan-mar; 14 (1): 171-76

concretização do processo de formar um novo perfil profissional. Além de servir de viga mestra no processo ensino-aprendizagem, esperava-se que esta metodologia servisse de contexto ao desempenho das ações de enfermagem ${ }^{2: 15}$.

Assim, o trabalho de enfermagem, quando voltado para a compreensão da situação-problema do cliente, tem como objetivo principal estimular a consciência crítica do profissional, ou do estudante de enfermagem quanto à resolução de problemas a partir das principais necessidades dos clientes, e não dar ênfase ao estudo das doenças com enfoque biomédico. A prática assistencial de enfermagem, em geral, é entendida por Santos e Figueiredo ${ }^{3}$ como relativa

[...] às condutas clínicas [clínico-assistenciais], que, na enfermagem, são realizadas para qualquer tipo de clientela, pois trazem em si os fundamentos de ações para atender aos doentes ou sadios, em fase diagnóstica, ou ainda [em função] de necessidades de manter a saúde $e^{3: 15}$.

Pode-se inferir que o intuito das enfermeiras tem a ver com a manutenção das condições da vida, evitar complicações, detectar sinais adversos, sintomas (signos) novos, de modo a agir para restaurar o bem-estar, o bem-viver do ser humano, estado geralmente reconhecido como saúde. ${ }^{3}$

A isso pode-se acrescentar que a prática assistencial, de um lado, é característica da prática da enfermagem centrada no cliente, e não exclusivamente na doença causadora do malestar ou desequilíbrio da saúde e motivo da hospitalização. A preocupação profissional, por outro lado, é com o corpo ${ }^{3}$ total (para nós é o lugar-sujeito do cuidado, onde nossa prática/arte acontece), onde a doença/mal-estar pode suceder como um evento na vida de todos. Além disso, a prática assistencial, na enfermagem clínico-hospitalar, busca apoiar-se em uma semiologia própria para a enfermagem, entendida essa como fundamental para a Enfermagem - que se aprende, que se ensina e que se pratica - cujo conhecimento se processa propiciando uma ciência do intelecto. Ciência que busca a evidência objetiva, considerando também os requisitos da arte do sentir subjetivo - dos sentidos, da sensibilidade, das emoções e das intuições humanas.

Cabe ressaltar que compreendemos o corpo, no cuidado de enfermagem, como um corpo vivo, pleno do sentido de viver, não apenas como objeto das ciências naturais. ${ }^{3}$ Mas, por ser um corpo movido por impulsos sensório-motrizes, subjacentes ao sensível e à sensibilidade - um corpo humano que pensa e racionaliza, e que também sonha, ama, sofre, imagina, cria, acredita, e enfrenta os desafios ou impasses do viver e do morrer. $^{3}$

Todavia, o conhecimento sobre as situações de enfermagem e seus graus de complexidade - menor, média e maior - ainda precisa ser ampliado com base nas investigações e nas práticas de ensinar a cuidare de aprender a cuidar. As características das situações de enfermagem exercem, por si, importante 
influência na definição de qual o cliente mais grave de uma enfermaria. Em geral, partimos do pressuposto de que, no interesse da enfermagem, é imprescindível o engajamento proposital de enfermeiras(os) com as situações-problema, ${ }^{2}$ como entendidas nos termos da hospitalização. Via de regra, à medida que elas (enfermeiras) se particularizam nas condições dos clientes envolvidos, alteram-se em seus graus de complexidade não só de ordem biológica (quadro clínico), mas também variam em razão de fatores psicológicas, ambientais e outros aliados à execução de procedimentos terapêuticos ou de cuidados de enfermagem.

\section{SOBRE AS SITUAÇÕES DE ENFERMAGEM}

Em realidade, precisamos definir, primeiramente, 0 significado de situação-problema, para a enfermagem, na prática assistencial hospitalar. Para tanto, é necessário tomar por base a própria situação de enfermagem. A princípio, a palavra situação equivale à condição de situar ou localizar o cliente em determinada realidade espacial e temporal. ${ }^{4}$ Também pode significar a realidade contingente a partir da qual se define a posição ou estado do ser do cliente que se encontra disposto, determinado, ou lançado em uma certa conjuntura. ${ }^{4}$ Em termos filosóficos, a situação é definida como aquela realidade pela qual se entende "[...] a relação do homem com o mundo, na medida em que limita, condiciona e, ao mesmo tempo, fundamenta e determina as possibilidades humanas como tais". ${ }^{4}$

Vale destacar que, em Filosofia, a situaçãoé uma das dez categorias aristotélicas, designando - o termo categoria - o predicado fundamenta/de uma coisa, de um objeto, ou o modo de ser do sujeito, por exemplo, como ele está: deitado, sentado, etc". ${ }^{5}$ Assim, "(...) as categorias são, além de substância (o próprio sujeito): quantidade, qualidade, relação, lugar, tempo, posição, estado ou situação, ação e paixão". ${ }^{5}$ Nesse sentido, as categorias conferem com as determinações mais diretas do objeto, correspondem às estruturas objetivas do ser - concepção filosófica objetivista - e são formas do pensamento, determinações do pensamento - concepção filosófica apriorística. $^{5}$

Ao refletirmos sobre essas concepções filosóficas, consideramos que a expressão situação-problema envolve muitos elementos, abrange aspectos que transcendem o que se pode perceber, o que conhecemos ou vivenciamos em qualquer momento da vida. Para Huxley,

Viver sempre foi uma situação-problema. Nossos antepassados, apesar de sua grande vontade de sobreviver, dispunham de poucos recursos (sobretudo tecnológicos) para isso. Podia haver falta de comida, o sol às vezes queimava e nem sempre iluminava ou aquecia a vida. Sabemos que ainda hoje isso ocorre para a maioria de nós. 0 mesmo vale para cada criança que nasce. Como mamífero, herdou o poder de ordenhar, mas seu reflexo está adaptado para uma mama da espécie. Contudo, em uma relação particular, como assimilar o leite, construindo sobre o reflexo da sucção, um esquema psicológico acomodado às características físicas e socioculturais daquela que alimenta a criança? Depois disso, mal tendo aprendido a mamar, logo nascem os dentes, o leite diminui ou seca, criando um novo contexto ou recorte para o qual os processos anteriores de acomodação agora são insuficientes. Diante dessa nova situação, como mobilizar recursos, alterar hábitos, atualizar esquemas de ação? Assim também acontece em outros momentos de nossa vida: mal nos tornamos adultos e precisamos refletir, tomar decisões relacionadas ao nosso envelhecimento. 6:15

Refletindo sobre o significado de situação-problema, a citação referida nos mostra que ela ocorre em todas as etapas do processo de vida e está sempre presente nos momentos em que o ser humano necessita enfrentar obstáculos para se adaptar, tomar decisões e buscar soluções para seu crescimento e aprendizagem. Viver é algo amplo e intenso, que envolve a existência humana, seus espaços, cultura, costumes, acrescentando desafios diversos. Uma característica importante da situação-problema é desafiar-nos para uma realização, de um lado, estruturada pelas coordenadas que lhe dão possibilidade e, de outro, que se expressa de pronto, em termos de aqui e agora. ${ }^{6}$ Contudo,

Um dos obstáculos de uma situação-problema é articular diversidade com singularidade. Diversidade porque sua álgebra pode ser expressa de muitos modos, ainda que cada caso seja único e demande uma compreensão que nunca se repete em sua singularidade ${ }^{2: 15}$.

Quando pensamos na prática assistencial de enfermagem, é interessante observar em que ponto ocorre tal articulação da diversidade com a singularidade. Vários clientes com o mesmo diagnóstico médico manifestam aspectos distintos e que, em cada caso, caracterizam uma "situação-problema" particular, singularizada, que poderá estar relacionada a quaisquer fatores, seja de ordem pessoal, emocional, institucional, ambiental, entre outros. Por exemplo, efetuar um banho no leito, ou auxiliar em um banho de aspersão, pode significar a distinção da função da Enfermagem diante das situações-problema. Fazer um curativo, administrar medicamentos e conversar com um cliente podem significar procedimentos que se repetem, cotidianamente, em muitas situações de enfermagem. Mas, o que não se repete é a relação do trabalho da enfermeira com a situação-problema ea 
Situações de enfermagem e graus de complexidade Queluci GC, Figueiredo NMA

execução de um mesmo procedimento - (auxílio no banho de aspersão ou a execução de um banho no leito) - com a necessidade particular de cada cliente. Nesse sentido, Carvalho, ao discorrer sobre obstáculos e implicações na abordagem às situações de enfermagem, descreve as características das situações-problemas na seguinte forma:

[...] As situações comportam componentes como a totalidade, as coisas ou fatos, o lugar, a duração, e os personagens. Mas cada situação é única, embora as situações de enfermagem possam assemelharse entre si. Isto permite que se aprenda com os dados da experiência concreta. As dificuldades na abordagem situacional surgem em razão de fatores ligados à ambiência social, ao índice crescente de transformações, às novidades e transitoriedade das coisas, às implicações psicológicas relativas aos erros de percepção, às dificuldades de adaptação, à incapacidade de fazer escolhas, e talvez a uma certa falta de coragem para assumir os riscos e os desafios de nosso tempo $0^{2: 15}$.

Nossa compreensão do assunto acerca das situaçõesproblema de clientes hospitalizados firma-se na proposição de Carvalho, especialmente em que pese as dificuldades da abordagem situacional, posto que " [...]) as situações-problema, em sua estrutura, envolvem: personagens; duração dos acontecimentos, espaço/ambiente (com transformações, novidades, transitoriedade, implicações, adaptações, incapacidades². É necessário identificar (clarear), nas investigações, as dificuldades das situações de enfermagem, as condições específicas dos clientes e os aspetos distintivos que podem diferençar uma dada situação-problema de uma outra qualquer, e como elas se manifestam na prática assistencial de enfermagem.

A autora ressalta, ainda, que "[...] as "situações de enfermagem são todas as situações humanas, na esfera do agir profissional, não importando a dimensão espaço-tempo em que elas se encontram e nem as distinções existentes nas pessoas assistidas"2. E acrescenta que essas situações podem ser encontradas nos domicílios, nas escolas e também nos demais espaços institucionalizados ou não.

$\mathrm{Na}$ definição de Carvalho e Castro $^{7}$, situações de enfermagem "(...) são o conjunto de circunstâncias da realidade espacial e temporal que afetam a saúde de indivíduos, grupos ou comunidades e em cuja esfera ocorre o encontro do enfermeiro com seu cliente". Vale registrar que as situaçõesproblema diferem, às vezes, quanto ao grau de complexidade não apenas porque são relacionadas com a sintomatologia do cliente, mas talvez pela soma das dificuldades na proporção de elementos presentes na trama do que ocorre em torno do cliente, elementos percebidos na experiência prática e que dão o sentido de problema à situação de enfermagem - entendida também como situação clínico-assistencial - que envolve o cliente, com certo grau de complexidade.

É importante dizer que uma situação de maior complexidade, por exemplo, nem sempre é a que se encontra somente nas unidades de terapia intensiva. Os clientes graves, por suposto, podem ser encontrados em qualquer unidade de cuidados intensivos. A distinção entre as situações de enfermagem por seus graus de complexidade pode se constituir como conferindo com um problema a ser definido. Na prática assistencial, o que se observa em geral é que a complexidade de uma situação é muito mais compreendida como acoplada ou ao somatório do aparato tecnológico ou à execução de procedimentos de enfermagem. Mas o que destacamos, por exemplo, é que a situação de um cliente entubado e conectado à prótese respiratória, com cateter de artéria pulmonar, nem sempre pode ser considerada mais complexa do que a de outro cliente hospitalizado em qualquer setor de clínica médica e que esteja somente com acesso venoso periférico. Às vezes, um banho de aspersão pode tornar-se mais complexo do que um banho no leito devido a diversos fatores relativos às condições de saúde do cliente, e que interferem no encontro enfermeiracliente em qualquer ambiente sujeito aos cuidados de enfermagem.

De acordo com Carvalho:

[...] as situações de enfermagem, com todos os seus fatores influentes e intercorrentes e perfeitamente inter-relacionados, não podendo ser pré-elaboradas, automaticamente observadas e arbitrariamente rotuladas, fatalmente terão de configurar-se a partir das próprias funções dos enfermeiros; fora desta perspectiva elas não têm sentido. Evidentemente, os enfermeiros, através do criterioso desempenho de suas funções, sejam quais forem as realidades em que se encontrem engajados, em vez de meros expectadores ou executores, tornam-se efetivamente os criadores e modeladores das situações de enfermagem que vivem, e de que participam ${ }^{8: 15}$.

Nestes termos, compreendemos que a concepção de situação-problema abrange fatores intrínsecos e extrínsecos no plano do que-pensare do que-fazer das enfermeiras, em sua própria prática. E a noção de complexidade aliada ao entendimento do conceito desta palavra, de uma forma geral, se deve, também, por suposto, às dificuldades das enfermeiras em identificar os problemas de enfermagem - evidentes e não evidentes - na prática assistencial, ${ }^{9}$ com efeito, haja vista todos os elementos que influenciam, ou podem influenciar, nas decisões e intervenções de enfermagem, estabelecendo um cer to tipo de complexidade durante a realização dos cuidados na prática de enfermagem. 
De acordo com Abdellah ${ }^{9}$, os problemas de enfermagem evidentes (overt nursing problem) condizem com condições enfrentadas pelo cliente e família, e nas quais a enfermeira pode assisti-los, ou ajudá-los, mediante o desempenho de suas funções profissionais (por exemplo: um cliente com úlcera de decúbito requer cuidado pela enfermeira para promover a cicatrização e/ou prevenir o surgimento de outras úlceras). Mas não é só isto. Um problema de enfermagem não evidente (covert nursing problem) confere com uma condição oculta, escondida, encoberta, mas enfrentada pelo cliente, às vezes sentida pela família, e em face da qual a enfermeira pode assisti-los ao desempenhar suas funções profissionais (por exemplo: um indivíduo traqueostomizado que, mesmo de retorno ao domićlio, está impossibilitado de dormir à noite pela ansiedade de ficar sozinho e sem poder pedir ajuda caso a cânula fique obstruída com secreções).

Para a autora, o problema de enfermagem "não evidente" é a ansiedade do cliente, nem sempre demonstrada também pela família, e cabe à enfermeira encontrar ocasião de instruir cliente e família, orientando-os sobre os meios para aliviar a ansiedade e proceder à desobstrução da cânula. Os problemas "não evidentes" são complexos, mormente porque podem se seguir de outras complicações e, assim, mais difíceis de serem identificados, visto que a própria singularidade do ser humano (cliente e família) ressalta-se pelas individualidades. Cada indivíduo, via de regra, está mais preocupado com seus problemas particulares; e isto se deve ao progresso biológico e tecnológico pelo qual o homem vive, mas não consegue experimentar subjetivamente os fatos em uma visão de totalidade. Segundo Huxley,.

[...] Ao menos teoricamente, deveria ser possível para o indivíduo ter uma experiência subjetiva direta do progresso e, até certo ponto, isso acontece. Porém, não experimentamos uma ação progressiva. (...) A vida humana em si é não-progressiva, ou seja, avança até certo ponto, permanece num planalto, depois desce $e^{10: 15}$.

Para o autor, a vida humana em si é não progressiva porque queremos viver em nossa vida pessoal, isolada e ilhada. Sendo assim, temos que compreender o contexto do mundo em que vivemos em sua totalidade, não entender as partes para depois visualizar o todo, e sim a situação como um todo a partir dos problemas que se apresentam em um momento específico.

\section{0 próprio autor ressalta que}

[...] Para uma criança nascida hoje, a televisão e aviões a jato são parte da ordem das coisas. Ela não tem idéia do tipo de mundo em que os adultos, mais idosos, foram criados, um mundo de cavalose trens, - de épocas anteriores -, embora essas coisas, que para ela [a criança] são curiosos legados neolíticos, ainda existam. Essa é outra razão pela qual é muito difícil experimentarmos o progresso subjetivamente, como se experimentam outros aspectos da vida pública e histórica; a maior parte de nós preocupa-se apenas com os fatos de nossas vidas privadas, relações familiares, brigas, ciúmes, compaixão, sexo e mexericos. Estamos unicamente envolvidos na vida da molécula, não na vida do gás 10:15.

Com base no pensamento de Huxley, podemos inferir, a partir de nossas experiências enquanto docentes na supervisão de alunos de enfermagem em campo da prática assistencial, que as enfermeiras manifestam dificuldades de identificar os problemas de enfermagem no contexto da situação do cliente, em um determinado momento, local, tempo e relacionamentos envolvidos. Quase sempre os problemas são identificados em suas ligações ou com o aparato tecnológico ou com os procedimentos técnicos executados, mesmo os de rotina.

0 entendimento, adequado ou inadequado, da complexidade resulta, quase sempre, de uma forma de compreensão insuficiente em relação aos aspectos que envolvem emoções, angústias ou outros sentimentos que requerem não só conhecimento teórico das enfermeiras, mas também a sensibilidade do corpo para trabalhar junto ao cliente e, ao mesmo tempo, saber tomar decisões apropriadas para a solução dos problemas presentes na situação de enfermagem. 0 organograma a seguir demonstra nosso entendimento acerca do que consistem as situações de enfermagem:

\section{Organograma}

Desdobramento conceitual de situação-problema: consequências e repercussões

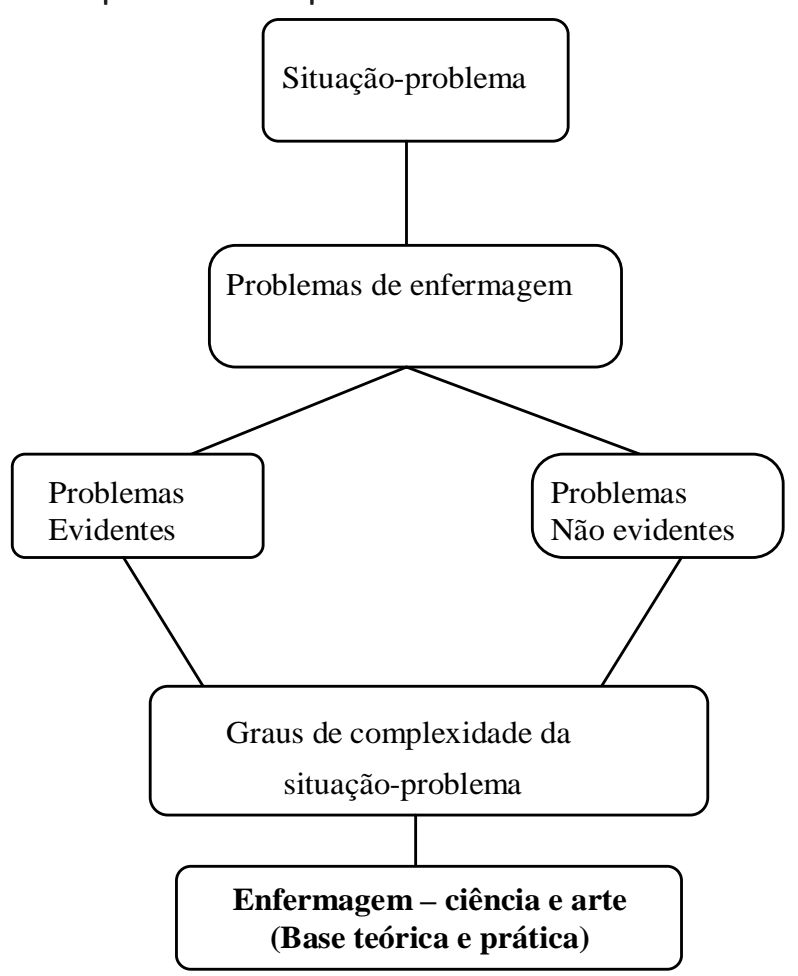

*Organograma elaborado pelas autoras 
Conforme o organograma, as situações de enfermagem incluem os problemas de enfermagem identificados (evidentes ou não evidentes). Os problemas evidentes, como também os não evidentes, permeiam todo o processo de enfermagem e podem estar presentes em relação a aspectos individuais do cliente no que tange à doença, família, aspectos clínicos (sintomatologia), aspectos ambientais ou institucionais ou outros.

Para a compreensão do desdobramento conceitual de situaç̃os-problema, Carvalho explica que a metodologia de resolução de situações-problema ${ }^{2}$ inclui: abordagem inicial à situação; levantamento (coleta de dados) da ambiência e do cliente; diagnóstico/descrição da situação de saúde (ambiente e cliente); planejamento das intervenções para resolução dos problemas identificados; execução das intervenções e avaliação da ajuda prestada. ${ }^{2}$ Os problemas pertinentes às situações devem ser objetivamente resolvidos por graus de complexidade - menor, média ou maior. Os cuidados de enfermagem são prestados, tanto quanto possível, conforme a sistemática do processo de enfermagem e de modo a atender especificamente às necessidades dos clientes e famílias a partir da situaçãoproblema que se encontram. Além disso, o que-pensare o quefazer das enfermeiras devem ser pautar pelos princípios científicos e conhecimentos fundamentais de Enfermagem ciência e arte.

\section{REFERÊNCIAS}

1- Carvalho V. acerca de uma educação apropriada à enfermagem em nossa época. In: Carvalho V. Enfermagem: ensino e perfil profissional. Rio de Janeiro (RJ): UFRJ/EEAN; 2006. p. 115-34.

2- Carvalho V. Sobre o projeto para aplicação de novas metodologias ao processo ensino-aprendizagem: a experiência de mudança curricular na Graduação da EEAN/UFRJ. In: Carvalho V. Sobre enfermagem: ensino e perfil profissional. Rio de Janeiro (RJ): UFRJ/ EEAN; 2006. p.159-75.

3- Figueiredo NMA, Santos I. Introduzindo a enfermagem clinica no ambiente terapêutico hospitalar. In: Santos I, et al. Enfermagem assistencial no ambiente hospitalar. São Paulo (SP): Atheneu; 2004. p. 3-20.

4- Abagnano N. Dicionário de filosofia. $4^{\mathrm{a}}$ ed. São Paulo (SP): Martins Fontes; 2000. p. 910.

5- Hessen J. Teoria do conhecimento. Tradução de João Vergílio Gallerani Cuter. $2^{\mathrm{a} e d .}$. São Paulo (SP): Martins Fontes; 2003.

6 - Perrenoud P, et al. As competências para ensinar no século XXI: a formação dos professores e o desafio da avaliação. Porto Alegre (RS): Artmed; 2002.

7- Carvalho V, Castro IB. Marco conceitual para o ensino e a pesquisa de enfermagem fundamental; um ponto de vista. Rev Bras Enferm 1985 jan./mar; 38 (1): 76-86.

\section{CONCLUSÃO}

Por conseguinte, partimos do pressuposto de que as situações-problema fazem parte não somente do processo de enfermagem, mas, de fato, do cotidiano das enfermeiras no panorama assistencial. As situações-problema incluem problemas evidentes e não evidentes, os quais estão relacionados ao cliente e família no âmbito da prática de enfermagem. Cada situação é única e, portanto, seus graus de complexidade - menor, média ou maior - não dependem somente da sintomatologia do cliente hospitalizado, mas também de outros aspectos presentes no encontro enfermeira-cliente que conferem um grau de complexidade a uma situação-problema singular.

Deste modo, o que se pode compreender por grau de complexidade de uma situação-problema não abrange apenas os sujeitos envolvidos, mas os cuidados de enfermagem e os fatores relacionados ao ambiente, mais claramente destacados e outros talvez obscuros, que podem interferir ou não na abordagem da enfermeira ao cliente durante a assistência. Assim, as situações como "recortes de um domínio complexo", se comparadas analiticamente entre si, certamente poderão interferir nas decisões das enfermeiras e podem comprometer a compreensão de todo o contexto assistencial. Portanto, as decisões de enfermagem podem, por sua vez, ser mais ou menos complexas, em vista do próprio entendimento do que possa estar interferindo em qualquer protocolo de tratamento préestabelecido.

8- Carvalho V. A problemática do diagnóstico de enfermagem. Separata do Boletim do Centro de Estudos $n^{0} 5$ do Ministério da Justiça/ Departamento de Administração e Divisão Pessoal; 1973.

9- Abdellah FG, et al. Patient - centered approaches to nursing. 2nd ed. New York(USA): Macmillan Company; 1960.

10 - Huxley A. A situação humana. Rio de Janeiro (RJ): Ed Globo; 1982.

Recebido em 21/05/2009 Reapresentado em 09/10/2009 Aprovado em 28/01/2010 